\title{
Kisspeptin and Polycystic Ovary Syndrome
}

\author{
Rong Tang ${ }^{1,2 \dagger}$, Xiaohong Ding ${ }^{3 \dagger}$ and Jianghu Zhu ${ }^{1,2,4 *}$ \\ ${ }^{1}$ Department of Pediatrics, The Second Affiliated Hospital of Wenzhou Medical University, Wenzhou, China, ${ }^{2}$ The Second \\ School of Medicine, Wenzhou Medical University, Wenzhou, China, ${ }^{3}$ The First Clinical Medical School, Wenzhou Medical \\ University, Wenzhou, China, ${ }^{4}$ Key Laboratory of Obstetric and Gynecologic and Pediatric Diseases and Birth Defects, \\ Ministry of Education, West China Second University Hospital, Sichuan University, Chengdu, China
}

Although the pathogenesis of Polycystic Ovary Syndrome (PCOS) is still unclear, the disturbance of hypothalamic-pituitary-gonadal (HPG) axis is suspected to be the main culprit in the development of PCOS. Kisspeptin, a hypothalamic peptide encoded by the KISS1 gene, is widely reported as a key factor in the regulation of luteinizing hormone $(\mathrm{LH})$ / follicular-stimulating hormone (FSH) secretion, which may be potentially involved with the development of PCOS.

OPEN ACCESS

Edited by:

Tom Kelsey,

University of St Andrews,

United Kingdom

Reviewed by:

Waljit Dhillo,

Imperial College London,

United Kingdom

Seunghyung Lee,

Kangwon National University,

South Korea

*Correspondence:

Jianghu Zhu

zhujianghu@wmu.edu.cn

tThese authors have contributed equally to this work

Specialty section: This article was submitted to Reproduction,

a section of the journa

Frontiers in Endocrinology

Received: 28 January 2019 Accepted: 25 April 2019

Published: 10 May 2019

Citation:

Tang R, Ding X and Zhu J (2019) Kisspeptin and Polycystic Ovary Syndrome. Front. Endocrinol. 10:298.

doi: 10.3389/fendo.2019.00298
Objective: The objective of this study is to summarize the existing knowledge in the literature in terms of the circulating kisspeptin concentration in PCOS women, kisspeptin and metabolic profiles in PCOS women and kisspeptin expression in PCOS animal models.

Method: A systematic literature search was conducted using "Pubmed," "Embase," "Web of Science" for all English language articles published up to July 2018 with the terms "PCOS," "Stein-Leventhal Syndrome," "Polycystic ovary syndrome," "metastins" and "kisspeptin".

Conclusion: Overall, kisspeptin levels are higher in the PCOS population, which supports the hypothesis that an over-active KISS1 system leads to enhanced HPG-axis activity, thereby causing irregular menstrual cycles and excessive androgen release in PCOS women.

Keywords: kisspeptin, polycystic ovary syndrome, reproduction, hypothalamus, metabolism

\section{INTRODUCTION}

Polycystic ovary syndrome (PCOS) is a common endocrine and metabolic disorder, which is characterized by chronic anovulation, polycystic ovaries and hyperandrogenism (1), affecting $5-22 \%$ of women of reproductive age (2). Although the pathogenesis of PCOS is still unclear, the disturbance of the hypothalamic-pituitary-gonadal (HPG) axis, featuring elevated luteinizing hormone (LH)/ follicular-stimulating hormone ( $\mathrm{FSH}$ ) ratios, is strongly suspected to be associated with the development of PCOS in about $35-90 \%$ patients (3-6). However, the mechanism involved with the dysregulated HPG axis in PCOS has not been well-illustrated yet.

Kisspeptin is a hypothalamic peptide encoded by the KISS1 gene, which was first isolated from the human placenta (7). Since it was discovered, substantial studies, based on the level of cell, animal model and even human-beings, reported a key role of kisspeptin in regulation of the HPG 


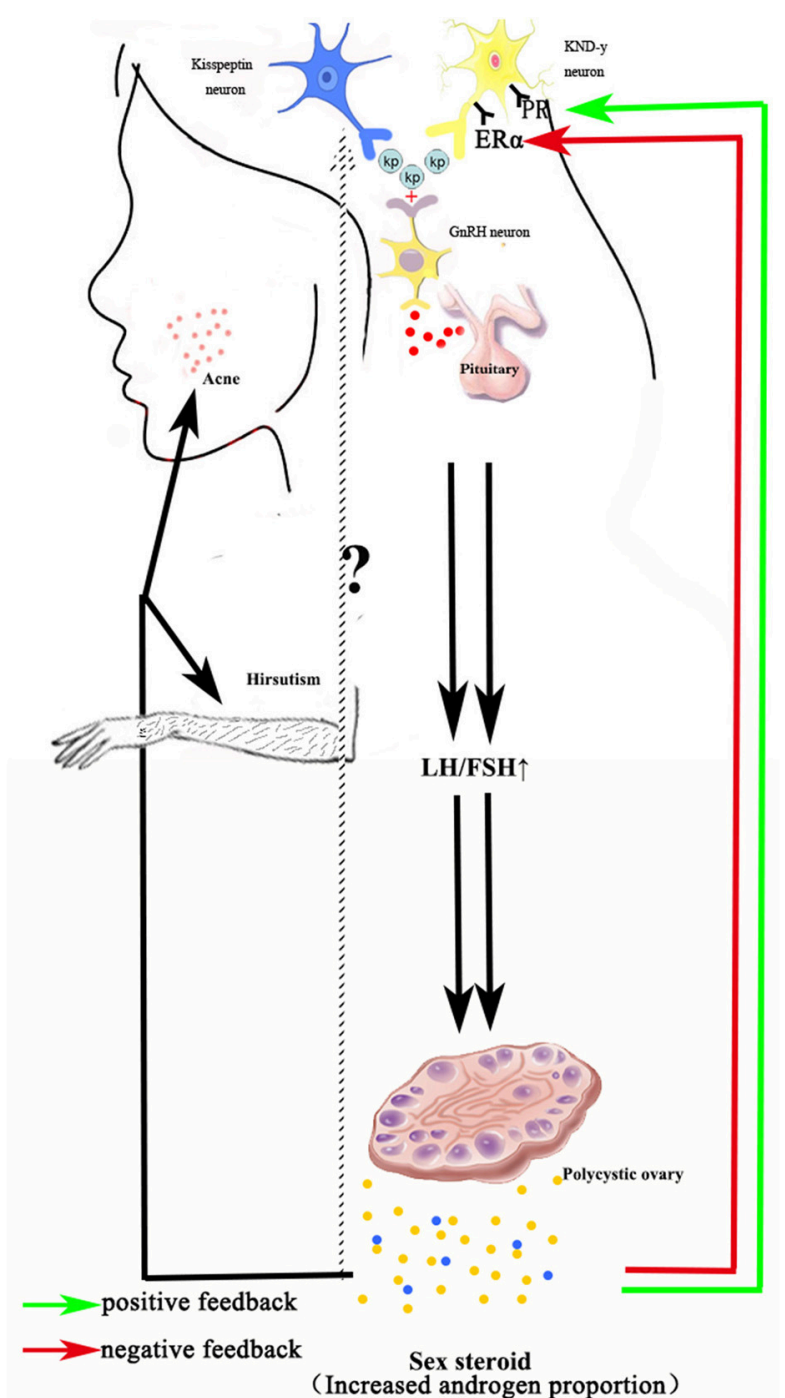

FIGURE 1 | Schematic diagram depicting how kisspeptin involved with PCOS. Both kisspeptin neuron and KND-y neuron can generate and release kisspeptin, which binds with the receptors expressed by $\mathrm{GnRH}$ neuron, facilitating the release of $\mathrm{GnRH}$. Therefore, over-expressed kisspeptin is expected to cause an enhanced HPG-axis activity, leading to a higher LH/FSH ratio and excessive androgen secretion, which disturbs the function and morphology of ovary and making acne and hirsutism more susceptible. KND-y neuron, Kisspeptin-Neurokinin B-Dynorphin Neuron; kp, Kisspeptin; GnRH Gonadotropin-Releasing Hormone; LH, Luteinizing Hormone; FSH, Follicular-stimulating Hormone; PR, Progesterone receptor; ER $\alpha$, Estrogen receptor- $\alpha$.

$\longrightarrow$ Feedback of sex steroid for KND-y neuron has been confirmed. - - - - $\rightarrow$ Feedback of steroid for Kisspeptin neuron has not been confirmed yet.

axis (8-12). Some studies observed that the administration of kisspeptin could lead to an over 2-fold increase in LH level, accompanied by a small or non-existent elevation of FSH level (13-15). Meanwhile, several researchers noted that kisspeptin exerts a direct effect on the upstream of GnRH neurons in terms of depolarization, higher firing rate and the up-regulated expression of GnRH mRNA, which explains the increased
$\mathrm{LH} / \mathrm{FSH}$ ratio after kisspeptin administration observed in those previous reports (16-19). Although the presence of kisspeptin receptors on pituitary has been reported, these receptors seemed to have little stimulatory effect on gonadotropin release when $\mathrm{GnRH}$ antagonist was applied, suggesting that the direct effect of kisspeptin on GnRH neurons is the major pathway $(20,21)$.

Although the above studies have unveiled the potential correlation between the KISS1 system and the HPG axis, whether the plasma/serum kisspeptin concentration is higher in PCOS women compared with general population remains inconclusive. Some studies observed a higher level of kisspeptin in PCOS women than controls $(22,23)$, while other studies showed comparable or negatively-correlated results $(24,25)$. However, according to the existing evidence of kisspeptin in regulating the HPG axis, it is biologically plausible that the number of kisspeptin neurons may be positively correlated with $\mathrm{LH}$ level (26). Therefore, plasma/serum kisspeptin levels can also be expected to be positively associated with serum LH level, although whether circulating kisspeptin levels reflect the number of kisspeptin neurons in the hypothalamus is not known.

Thus, it is necessary to summarize the existing knowledge with regards to the relationship between PCOS and kisspeptin in the literature and review whether circulating kisspeptin concentrations are increased in women with PCOS. Figure out the underlying role of kisspeptin involved with the pathogenesis of PCOS may provide valuable information and directions for future studies (Figure 1).

\section{METHOD}

A systematic literature search was conducted using "Pubmed," "Embase," "Web of Science" for all English language articles published up to July 2018 with the terms "PCOS," "SteinLeventhal Syndrome," "Polycystic ovary syndrome," "metastins" and "kisspeptin". The final item for retrieve is "(((Stein-Leventhal Syndrome) [Title/Abstract] OR (PCOS) [Title/Abstract] OR (Polycystic Ovarian Syndrome) [Title/Abstract])) AND ((Metastins[Title/Abstract] OR kisspeptin)[Title/Abstract])".

\section{KISSPEPTIN LEVELS IN WOMEN WITH PCOS}

Since Panidis et al firstly compared the kisspeptin level between PCOS women and non-PCOS females (24), a total of 12 studies were subsequently conducted during the last decade, contributing to investigate the relationship between plasma/serum kisspeptin level and the presence of PCOS (shown in Table 1). It was biologically plausible that the kisspeptin level should be higher in PCOS women according to previously in vivo/vitro findings (8-12). As expected, eight out of twelve studies, to the best of our knowledge, have reported a higher kisspeptin level in PCOS women compared with controls. Among the other four studies, Albalawi et al did not keep the comparability of age and BMI between PCOS and nonPCOS group, and they only considered "oligomenorrhoea" and "abnormal ovary" into the diagnosis criteria of PCOS (25). 
TABLE 1 | Comparison of kisspeptin level between PCOS women and control group.

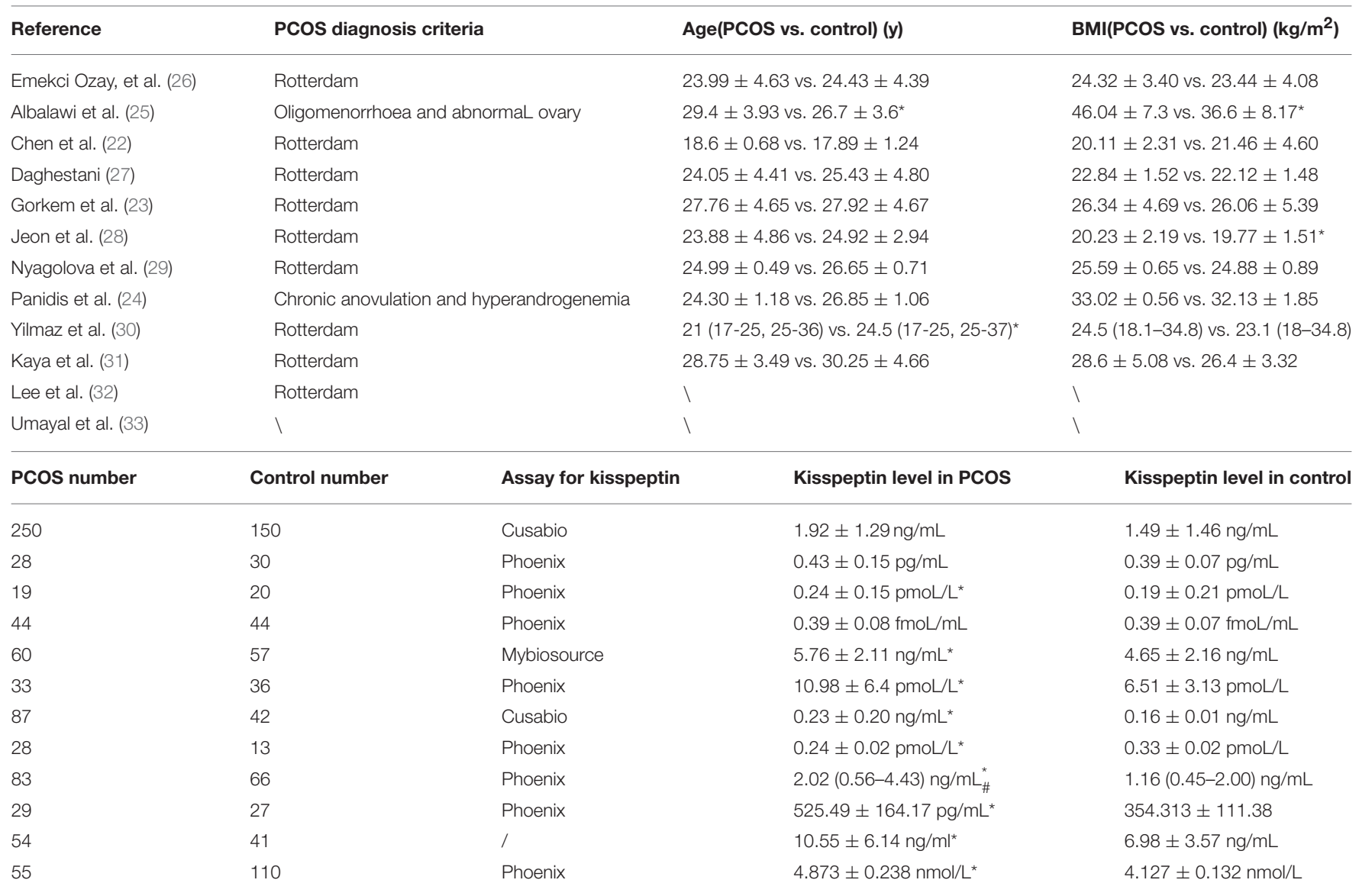

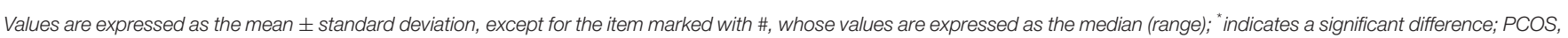
Polycystic ovary syndrome; BMI, Body mass index; \, Data could not be found in conference articles and unpublished data.

TABLE 2 | The relationship between kisspeptin and metabolic profiles in PCOS women.

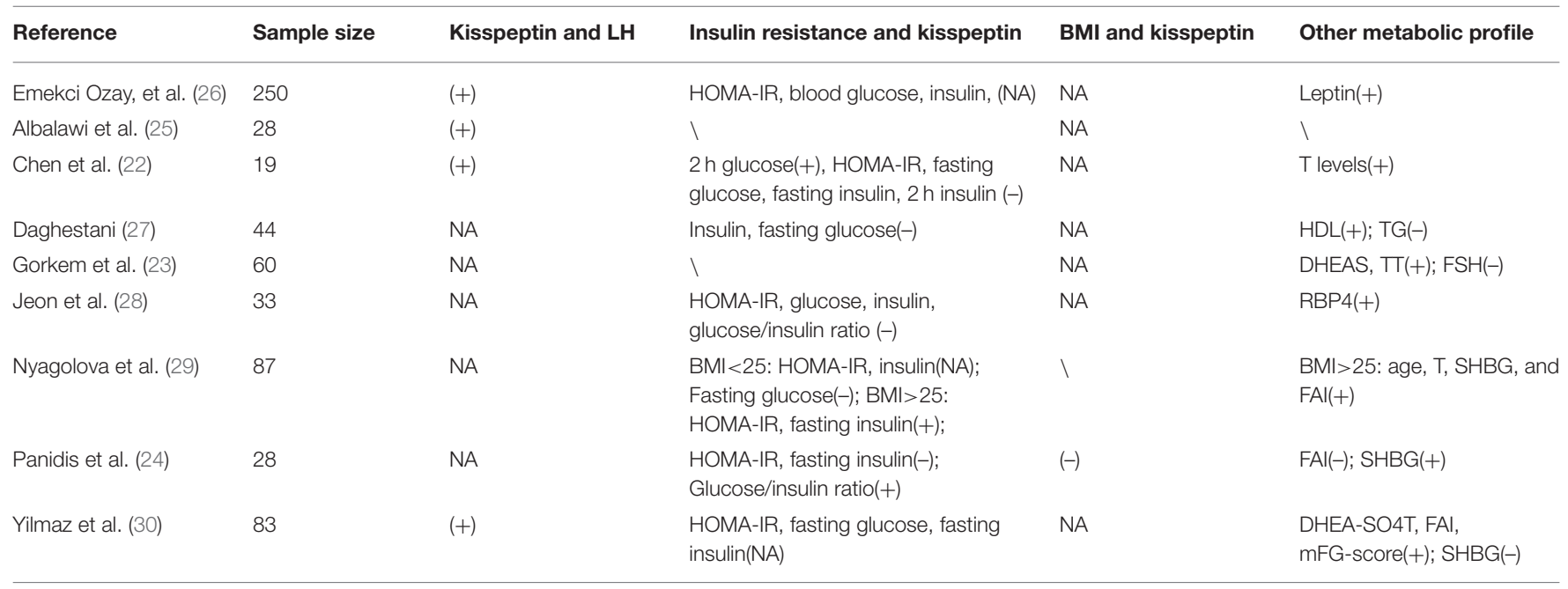

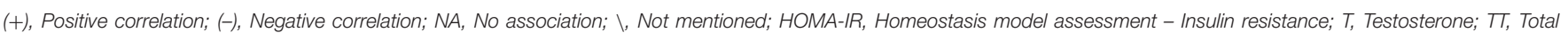

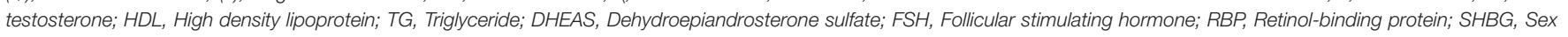
hormone binding globulin; FAl, Free androgen index; $\mathrm{mFG}$ - score, modified Ferriman-Gallwey score. 
Similarly, Panidis et al only considered "Chronic anovulation" and "hyperandrogenemia" as the diagnostic norm when they enrolled participants in their trials (24). Actually, different PCOS phenotypes are characterized by various metabolic features, raising the possibility that the kisspeptin level may not be increased in all subtypes. A high proportion of one PCOS phenotype with normal kisspeptin levels potentially distorts the measured kisspeptin concentration in the whole sample, which could partially explain the negative findings reported in some studies. However, while some rodents studies provided persuasive evidence, none of the existing studies has exclusively evaluated the kisspeptin level in each subtype of PCOS patients. The other reason to explain the negative finding in some studies may be the small sample size, varying from only 58 to 400 patients, which is susceptible to cause unexpected sampling error. Actually, aside from hypothalamic overactivity, some other factors such as pituitary and ovarian dysfunction may also contribute at least partially to the development of PCOS. For some PCOS patients, hypothalamic overactivity might be less severe than ovarian dysfunction, while the role of kisspeptin in the ovary has rarely been reported previously and is seemingly insignificant, which explains why these patients show PCOS symptoms, but elevated kisspeptin levels are not detected in their blood. In conclusion, while this review stated kisspeptin levels are higher in women with PCOS compared with controls according to qualitative literature-based evidence, the theory that not all PCOS subtypes could show higher kisspeptin levels should be investigated in future studies.

\section{KISSPEPTIN AND METABOLIC PROFILES IN WOMEN WITH PCOS}

Kisspeptin was reported to be an effective stimulator of pulsatile $\mathrm{GnRH}$ release, which predominantly determines circulating levels of LH. Thus, it is not surprising to find a positive correlation between kisspeptin and LH concentration. However, the majority of studies failed to provide adequate statistical evidence to support this theory. Although Gorkem et al observed a higher concentration of kisspeptin in PCOS women compared with their non-PCOS counterparts (23), kisspeptin and LH levels were not correlated, in line with two other small observational studies $(28,29)$. In addition, while several investigators noticed a positive correlation between kisspeptin level and $\mathrm{LH}$, they failed to find a significantly higher kisspeptin level in PCOS women compared with control group $(25,26)$. A recent study may help explain this phenomenon by providing compelling evidence that in patients with PCOS, spontaneous episodic kisspeptin secretion was coupled with LH pulses only in patients without oligomenorrhoea (34). Patients with oligomenorrhea did not demonstrate coupling of kisspeptin pulses with LH pulsatility, suggesting that kisspeptin's regulation of the HPG-axis had been disturbed already. Therefore, due to the heterogeneous constitution of patients with/without oligomenorrhea in different studies, the relationship between kisspeptin and LH secretion is not clear.

Insulin resistance (IR) is found in 50 to $70 \%$ of women with PCOS (35), which is widely accepted as a significant risk factor for developing the metabolic syndrome. However, the interaction between kisspeptin and IR in PCOS patients has not been clarified yet. Therefore, in this review, we summarized the existing evidence which is conflicting in terms of the relationship between kisspeptin and IR. Although two cell-based studies found that kisspeptin could inhibit insulin secretion $(36,37)$, Bowe et al did not demonstrate any change in insulin secretion after kisspeptin was administered (38). In vitro studies have demonstrated that kisspeptin facilitated the secretion of glucose-induced insulin in human, porcine, murine islets (39-41). Recently, Izzi-Engbeaya et al demonstrated a beneficial role of kisspeptin in insulin secretion in humans in vivo for the first time, which has significant implications for our understanding of the relationship between metabolism and reproduction (42). In women with PCOS, Nyagolova et al. noticed a positive correlation between kisspeptin levels and homeostatic model assessment (HOMA)-IR

TABLE 3 | Kisspeptin expression in PCOS animal models.

\begin{tabular}{|c|c|c|c|}
\hline Reference & PCOS model & Model characteristics & Main conclusion \\
\hline Aliabadi et al. (47) & Letrozole-induced & $\begin{array}{l}\text { Irregular diestrus; Persistent anovulation; Polycystic } \\
\text { ovary; Testosterone }(\uparrow) \text { and } \mathrm{LH}(\uparrow) ; \mathrm{EG}(\downarrow)\end{array}$ & $\begin{array}{l}\text { In ARC nucleus, kisspeptin - positive cells }(\uparrow) \text {; } \\
\text { In AVPV nucleus, kisspeptin-positive cells }(\downarrow)\end{array}$ \\
\hline Brown et al. (48) & DHT-induced & Body weight( $\uparrow) ;$ Insulin resistance & $\begin{array}{l}\text { Hypothalamic KISS1 mRNA and kisspeptin } \\
\text { immunoreactivity }(\downarrow)\end{array}$ \\
\hline Kondo et al. (49) & RU486 exposure & Irregular cycles; Testosterone $(\uparrow)$ and $\mathrm{LH}(\uparrow)$ & Hypothalamus kisspeptin-positive cells ( $\uparrow)$ \\
\hline Marcondes et al. (50) & $\begin{array}{l}\text { Neonatal exposure of } \\
E G / T G\end{array}$ & $\begin{array}{l}\text { EG: anovulation and Polycystic ovaries; LH(-), } \\
\text { Testosterone(-); } \\
\text { TG: LH ( } \uparrow) \text { and Testosterone ( } \uparrow) \text {; Anovulation; } \\
\text { Polycystic ovaries }\end{array}$ & $\begin{array}{l}\text { EG: KISS1 }(\downarrow), \operatorname{KISS} 1 r(\uparrow) \\
\text { TG: KISS1 }(\downarrow)\end{array}$ \\
\hline Matsuzaki et al. (51) & Letrozole-induced & $\begin{array}{l}\text { Irregular diestrus; Persistent anovulation; } \\
\text { Polycystic ovary; Testosterone }(\uparrow) \text { and } L H(\uparrow) ; E G(\downarrow)\end{array}$ & In ARC: Kisspeptin mRNA expression( $\uparrow)$ \\
\hline Kondo et al. (49) & $\begin{array}{l}\text { 1.Postnatal DHT exposure } \\
\text { 2.Prenatal DHT exposure }\end{array}$ & $\begin{array}{l}\text { Body weight }(\uparrow) \text {; Persistent diestrus; LH(-); Irregular } \\
\text { diestrus; } \mathrm{LH}(\uparrow) \text { Body weight(-) }\end{array}$ & $\begin{array}{l}\text { 1. In } A R C, \text { kisspeptin immunoreactivity }(-) \\
\text { 2. In } A R C, \text { kisspeptin/NKB immunoreactivity ( } \uparrow)\end{array}$ \\
\hline
\end{tabular}


as well as fasting insulin concentrations in obese participants, which is consistent with a previous Chinese study reporting that two-hour glucose concentrations are positively correlated with kisspeptin levels (22). Nonetheless, another study found that fasting insulin concentration and HOMA-IR were negatively correlated with kisspeptin, meanwhile, glucose/insulin ratio turned out to be positively associated with kisspeptin level (24). Overall, limited and conflicted information is provided in the literature for us to claim an unequivocal conclusion pertaining to the relationship between kisspeptin and IR in general population, let alone in PCOS patients. Due to the heterogeneity of PCOS, future studies should be designed to investigate the dynamic interaction between kisspeptin and glucose tolerance based on different subtypes of PCOS.

Several other metabolic markers, the plasma concentration of testosterone, dehydroepiandrosterone sulfate, free androgen index, leptin, retinol-binding protein, high density lipoprotein and sex hormone binding globulin, have been reported to be positively correlated with kisspeptin at least once and summarized in Table 2. It seems that kisspeptin level is not associated with BMI because only one study found that it is negatively correlated with kisspeptin in logistic regression analysis (24).

\section{KISSPEPTIN EXPRESSION IN ANIMAL MODELS OF PCOS}

Two main kisspeptin neuron populations have been described in rodents, which are located in the hypothalamic ARC and AVPV (43). Kisspeptin neurons in the ARC nucleus are considered a more important kisspeptin generator than those in the AVPV of rodents, which are called KND-y neurons. These neurons autosynaptically regulate pulsatile secretion of kisspeptin through neurokinin $B$ receptors and kappa opioid peptide receptors (44). Although some evidence suggested that kesspeptin matters in the physiological regulation of HPG axis $(45,46)$, the function of KISS1 system in the pathogenesis of PCOS is still unclear. Recently, several studies measured the expression of the KISS1 gene and kisspeptin immunoreactivity in PCOS rat model (shown in Table 3), suggesting that the KISS1 system acts differently in various PCOS models. Brown et al. found that hypothalamic KISS1 mRNA and kisspeptin immunoreactivity is reduced in DHT(dihydrotestosterone)induced PCOS rat models, which was the first attempt to note an androgenic effect on hypothalamic KISS1 in female rats (48). Subsequently, down-regulated expression of the KISS1 gene was also detected in two rat models induced by testosterone and estradiol respectively. The KISS1 receptor gene, however, was only upregulated in the estradiol-induced model (50). In

\section{REFERENCES}

1. Tsilchorozidou T, Overton C, Conway GS. The pathophysiology of polycystic ovary syndrome. Clin Endocrinol. (2004) 60:1-17. doi: 10.1046/j.1365-2265.2003.01842.x contrast, a recent study failed to find a difference in kisspeptinimmunoreactivity in postnatal DHT-induced rats compared with controls as observed in the study conducted by Brown et al. However, they observed increased KISS1 expression in the prenatal DHT-induced PCOS model (52). Two letrozole-induced PCOS rat models, featuring irregular cycles, elevated serum LH and testosterone levels presented new findings. The authors noticed more kisspeptin-positive cells in the ARC nucleus but less in the AVPV nucleus (47). The other study also found kisspeptin mRNA expression increased in the ARC instead of the AVPV, which supports a theory that the ARC serves as a more important regulator of KISS1 system in the PCOS animal model (51). In addition, increased hypothalamic kisspeptinpositive cells were also reported in a RU486 (mifepristone)induced rat (49). Therefore, animal models of PCOS with distinct metabolic phenotypes may result in varying kisspeptin expression in different parts of the hypothalamus. In this review, an interesting conclusion is that the KISS1 system is overactivated only in the animal models with elevated LH levels, in line with the presumed function of kisspeptin in the regulation of the HPG-axis. Besides, kisspeptin immunoreactivity is decreased in the PCOS rats with higher weight, which suggested that body weight is negatively correlated with the activity of KISS1 system. In conclusion, findings from animal models suggested that the KISS1 system only upregulated in the PCOS phenotypes with higher LH levels and normal body weight.

\section{CONCLUSION}

Overall, kisspeptin levels are higher in the PCOS population, which supports the hypothesis that an over-active KISS1 system causes HPG-axis overactivity, leading to irregular menstrual cycles and excessive androgen release. However, findings from animal studies suggest that kisspeptin levels are not increased in all subtypes of PCOS. In this review, although we conclude that kisspeptin concentration is elevated in the subtypes of PCOS featured with higher LH levels and normal body weight, some of the changes in animal models reflect more about the way the "PCOS model" is generated rather than unveiling too much pathophysiologic change about PCOS in humans. Future studies investigating the relationships between kisspeptin and other metabolic factors such as LH and IR, which are still unclear, would be warranted.

\section{AUTHOR CONTRIBUTIONS}

RT and XD were engaged in analysis of data, prepared, and drafted manuscript. JZ contributed to conception, study design, and article revision. 
women with polycystic ovary syndrome. J Clin Endocrinol Metab. (1997) 82:2248-56. doi: 10.1210/jcem.82.7.4105

4. Baldani DP, Skrgatic L, Goldstajn MS, Zlopasa G, Oguic SK, Canic T, et al. Clinical and biochemical characteristics of polycystic ovary syndrome in Croatian population. Coll Antropol. (2012) 36:1413-8.

5. Li L, Chen X, He Z, Zhao X, Huang L, Yang D. Clinical and metabolic features of polycystic ovary syndrome among Chinese adolescents. J Pediatr Adolesc Gynecol. (2012) 25:390-5. doi: 10.1016/j.jpag.2012.07.006

6. Ates S, Sevket O, Sudolmus S, Dane B, Ozkal F, Uysal O, et al. Different phenotypes of polycystic ovary syndrome in Turkish women: clinical and endocrine characteristics. Gynecol Endocrinol. (2013) 29:931-5. doi: 10.3109/09513590.2013.819082

7. Ohtaki T, Shintani Y, Honda S, Matsumoto H, Hori A, Kanehashi K, et al. Metastasis suppressor gene KiSS-1 encodes peptide ligand of a G-proteincoupled receptor. Nature. (2001) 411:613-7. doi: 10.1038/35079135

8. De Bond JA, Li Q, Millar RP, Clarke IJ, Smith JT. Kisspeptin signaling is required for the luteinizing hormone response in anestrous ewes following the introduction of males. PLOS ONE. (2013) 8:e57972. doi: 10.1371/journal.pone.0057972

9. Kotani M, Katagiri F, Hirai T, Kagawa J. Plasma kisspeptin levels in male cases with hypogonadism. Endocr J. (2014) 61:1137-40. doi: 10.1507/endocrj.EJ14-0137

10. Iijima N, Takumi K, Matsumoto K, Ozawa H. Visualization of kisspeptin binding to rat hypothalamic neurons. Acta Histochem Cytochem. (2015) 48:179-84. doi: 10.1267/ahc.15017

11. Oride A, Kanasaki H, Mijiddorj T, Sukhbaatar U, Ishihara T, Kyo S. Regulation of kisspeptin and gonadotropin-releasing hormone expression in rat placenta: study using primary cultures of rat placental cells. Reprod Biol Endocrinol. (2015) 13:90. doi: 10.1186/s12958-015-0083-3

12. Xie C, Jonak CR, Kauffman AS, Coss D. Gonadotropin and kisspeptin gene expression, but not GnRH, are impaired in cFOS deficient mice. Mol Cell Endocrinol. (2015) 411:223-31. doi: 10.1016/j.mce.2015.04.033

13. Dhillo WS, Chaudhri OB, Patterson M, Thompson EL, Murphy KG, Badman MK, et al. Kisspeptin-54 stimulates the hypothalamic-pituitary gonadal axis in human males. J Clin Endocrinol Metab. (2005) 90:6609-15. doi: 10.1210/jc.2005-1468

14. Messager S, Chatzidaki EE, Ma D, Hendrick AG, Zahn D, Dixon J, et al. Kisspeptin directly stimulates gonadotropin-releasing hormone release via G protein-coupled receptor 54. Proc Natl Acad Sci USA. (2005) 102:1761-6. doi: 10.1073/pnas.0409330102

15. Jayasena CN, Abbara A, Veldhuis JD, Comninos AN, Ratnasabapathy R, De Silva A, et al. Increasing LH pulsatility in women with hypothalamic amenorrhoea using intravenous infusion of Kisspeptin-54. J Clin Endocrinol Metab. (2014) 99:E953-61. doi: 10.1210/jc.2013-1569

16. Han SK, Gottsch ML, Lee KJ, Popa SM, Smith JT, Jakawich SK, et al. Activation of gonadotropin-releasing hormone neurons by kisspeptin as a neuroendocrine switch for the onset of puberty. J Neurosci. (2005) 25:1134956. doi: 10.1523/jneurosci.3328-05.2005

17. Zhang C, Roepke TA, Kelly MJ, Ronnekleiv OK. Kisspeptin depolarizes gonadotropin-releasing hormone neurons through activation of TRPC-like cationic channels. J Neurosci. (2008) 28:4423-34. doi: 10.1523/jneurosci.5352-07.2008

18. Novaira HJ, Ng Y, Wolfe A, Radovick S. Kisspeptin increases GnRH mRNA expression and secretion in GnRH secreting neuronal cell lines. Mol Cell Endocrinol. (2009) 311:126-34. doi: 10.1016/j.mce.2009.06.011

19. Oakley AE, Clifton DK, Steiner RA. Kisspeptin signaling in the brain. Endocr Rev. (2009) 30:713-43. doi: 10.1210/er.2009-0005

20. Irwig MS, Fraley GS, Smith JT, Acohido BV, Popa SM, Cunningham MJ, et al. Kisspeptin activation of gonadotropin releasing hormone neurons and regulation of KiSS-1 mRNA in the male rat. Neuroendocrinology. (2004) 80:264-72. doi: $10.1159 / 000083140$

21. Castellano JM, Navarro VM, Fernandez-Fernandez R, Nogueiras R, Tovar S, Roa J, et al. Changes in hypothalamic KiSS-1 system and restoration of pubertal activation of the reproductive axis by kisspeptin in undernutrition. Endocrinology. (2005) 146:3917-25. doi: 10.1210/en.2005-0337

22. Chen X, Mo Y, Li L, Chen Y, Li Y, Yang D. Increased plasma metastin levels in adolescent women with polycystic ovary syndrome. Eur J Obstet Gynecol Reprod Biol. (2010) 149:72-6. doi: 10.1016/j.ejogrb.2009.11.018
23. Gorkem U, Togrul C, Arslan E, Sargin Oruc A, Buyukkayaci Duman N. Is there a role for kisspeptin in pathogenesis of polycystic ovary syndrome? Gynecol Endocrinol. (2018) 34:157-60. doi: 10.1080/09513590.2017.13 79499

24. Panidis D, Rousso D, Koliakos G, Kourtis A, Katsikis I, Farmakiotis D, et al. Plasma metastin levels are negatively correlated with insulin resistance and free androgens in women with polycystic ovary syndrome. Fertil Steril. (2006) 85:1778-83. doi: 10.1016/j.fertnstert.2005.11.044

25. Albalawi FS, Daghestani MH, Daghestani MH, Eldali A, Warsy AS. rs4889 polymorphism in KISS1 gene, its effect on polycystic ovary syndrome development and anthropometric and hormonal parameters in Saudi women. J Biomed Sci. (2018) 25:50. doi: 10.1186/s12929-018-0452-2

26. Emekci Ozay O, Ozay AC, Acar B, Cagliyan E, Secil M, Kume T. Role of kisspeptin in polycystic ovary syndrome (PCOS). Gynecol Endocrinol. (2016) 32:718-22. doi: 10.3109/09513590.2016.1161019

27. Daghestani MH. Evaluation of biochemical, endocrine, and metabolic biomarkers for the early diagnosis of polycystic ovary syndrome among non-obese Saudi women. Int J Gynaecol Obstet. (2018) 142:162-9. doi: 10.1002/ijgo.12527

28. Jeon YE, Lee KE, Jung JA, Yim SY, Kim H, Seo SK, et al. Kisspeptin, leptin, and retinol-binding protein 4 in women with polycystic ovary syndrome. Gynecol Obstet Invest. (2013) 75:268-74. doi: 10.1159/000350217

29. Nyagolova P, Mitkov M, Orbetzova M, Terzieva D, Koleva D. Kisspeptin and galanin-like peptide (GALP) relationship in women with polycystic ovary syndrome (PCOS). Gynecol Endocrinol. (2016) 32:136. doi: 10.3109/09513590.2016.1150635

30. Yilmaz SA, Kerimoglu OS, Pekin AT, Incesu F, Dogan NU, Celik C, et al. Metastin levels in relation with hormonal and metabolic profile in patients with polycystic ovary syndrome. Eur J Obstet Gynecol Reprod Biol. (2014) 180:56-60. doi: 10.1016/j.ejogrb.2014.06.004

31. Kaya C, Alay I, Babayeva G, Gedikbasi A, Ertas Kaya S, Ekin M, et al. Serum Kisspeptin levels in unexplained infertility, polycystic ovary syndrome, and male factor infertility. Gynecol Endocrinol. (2019) 35:228-32. doi: 10.1080/09513590.2018.1519792

32. Lee K, Choi YS, Yang H, Seo SK, Kim HY, Lee BS. Kisspeptin, leptin and retinol-binding protein-4 in women with polycystic ovary syndrome. Hum Reprod. (2010) 25:i67-9. doi: 10.1093/humrep/de.25.s1.45

33. Umayal B, Jayakody SN, Chandrasekharan NV, Wijesundera WS, Wijeyaratne CN. Polycystic ovary syndrome (PCOS) and kisspeptin - A Sri Lankan study. J Postgrad Med. (2019) 65:18-23. doi: 10.4103/jpgm.JPGM_683_17

34. Katulski K, Podfigurna A, Czyzyk A, Meczekalski B, Genazzani AD. Kisspeptin and LH pulsatile temporal coupling in PCOS patients. Endocrine. (2018) 61:149-57. doi: 10.1007/s12020-018-1609-1

35. Legro RS, Castracane VD, Kauffman RP. Detecting insulin resistance in polycystic ovary syndrome: purposes and pitfalls. Obstet Gynecol Surv. (2004) 59:141-54. doi: 10.1097/01.ogx.0000109523.25076.e2

36. Silvestre RA, Egido EM, Hernandez R, Marco J. Kisspeptin-13 inhibits insulin secretion without affecting glucagon or somatostatin release: study in the perfused rat pancreas. J Endocrinol. (2008) 196:283-90. doi: $10.1677 /$ joe- $07-0454$

37. Vikman J, Ahren B. Inhibitory effect of kisspeptins on insulin secretion from isolated mouse islets. Diabetes Obes Metab. (2009) 11(suppl. 4):197-201. doi: 10.1111/j.1463-1326.2009.01116.x

38. Bowe JE, King AJ, Kinsey-Jones JS, Foot VL, Li XF, O’Byrne KT, et al. Kisspeptin stimulation of insulin secretion: mechanisms of action in mouse islets and rats. Diabetologia. (2009) 52:85-62. doi: 10.1007/s00125-009-1283-1

39. Hauge-Evans AC, Richardson CC, Milne HM, Christie MR, Persaud SJ, Jones PM. A role for kisspeptin in islet function. Diabetologia. (2006) 49:2131-5. doi: $10.1007 / \mathrm{s} 00125-006-0343-z$

40. Bowe JE, Foot VL, Amiel SA, Huang GC, Lamb MW, Lakey J, et al. GPR54 peptide agonists stimulate insulin secretion from murine, porcine and human islets. Islets. (2012) 4:20-3. doi: 10.4161/isl.18261

41. Schwetz TA, Reissaus CA, Piston DW. Differential stimulation of insulin secretion by GLP-1 and Kisspeptin-10. PLoS ONE. (2014) 9:e113020. doi: 10.1371/journal.pone. 0113020

42. Izzi-Engbeaya C, Comninos AN, Clarke SA, Jomard A, Yang L, Jones S, et al. The effects of kisspeptin on beta-cell function, serum metabolites and appetite in humans. Diabetes Obes Metab. (2018) 20:2800-10. doi: 10.1111/dom.13460 
43. Clarkson J, d'Anglemont de Tassigny X, Colledge WH, Caraty A, Herbison AE. Distribution of kisspeptin neurones in the adult female mouse brain. $J$ Neuroendocrinol. (2009) 21:673-82. doi: 10.1111/j.1365-2826.2009.01892.x

44. Herbison AE, de Tassigny X, Doran J, Colledge WH. Distribution and postnatal development of Gpr54 gene expression in mouse brain and gonadotropin-releasing hormone neurons. Endocrinology. (2010) 151:312-21. doi: 10.1210/en.2009-0552

45. Navarro VM, Gottsch ML, Chavkin C, Okamura H, Clifton DK, Steiner RA. Regulation of gonadotropin-releasing hormone secretion by kisspeptin/dynorphin/neurokinin B neurons in the arcuate nucleus of the mouse. J Neurosci. (2009) 29:11859-66. doi: 10.1523/jneurosci.1569-09.2009

46. Billings HJ, Connors JM, Altman SN, Hileman SM, Holaskova I, Lehman MN, et al. Neurokinin B acts via the neurokinin-3 receptor in the retrochiasmatic area to stimulate luteinizing hormone secretion in sheep. Endocrinology. (2010) 151:3836-46. doi: 10.1210/en.2010-0174

47. Aliabadi E, Namavar MR, Mortezaee K, Toolee H, Keshtgar S, Mirkhani $\mathrm{H}$, et al. Kisspeptin expression features in the arcuate and anteroventral periventricular nuclei of hypothalamus of letrozole-induced polycystic ovarian syndrome in rats. Arch Gynecol Obstet. (2017) 296:957-63. doi: 10.1007/s00404-017-4509-3

48. Brown RE, Wilkinson DA, Imran SA, Caraty A, Wilkinson M. Hypothalamic kiss1 mRNA and kisspeptin immunoreactivity are reduced in a rat model of polycystic ovary syndrome (PCOS). Brain Res. (2012) 1467:1-9. doi: 10.1016/j.brainres.2012.05.049

49. Kondo M, Osuka S, Iwase A, Nakahara T, Saito A, Bayasula et al. Increase of kisspeptin-positive cells in the hypothalamus of a rat model of polycystic ovary syndrome. Metab Brain Dis. (2016) 31, 673-681. doi: 10.1007/s11011-016-9807-0

50. Marcondes RR, Carvalho KC, Giannocco G, Duarte DC, Garcia N, SoaresJunior JM, et al. Hypothalamic transcriptional expression of the kisspeptin system and sex steroid receptors differs among polycystic ovary syndrome rat models with different endocrine phenotypes. Clinics. (2017) 72:510-4. doi: 10.6061/clinics/2017(08)09

51. Matsuzaki T, Tungalagsuvd A, Iwasa T, Munkhzaya M, Yanagihara R, Tokui T, et al. Kisspeptin mRNA expression is increased in the posterior hypothalamus in the rat model of polycystic ovary syndrome. Endocr J. (2017) 64:7-14. doi: 10.1507/endocrj.EJ16-0282

52. Osuka S, Iwase A, Nakahara T, Kondo M, Saito A, Bayasula et al. Kisspeptin in the hypothalamus of 2 rat models of polycystic ovary syndrome. Endocrinology. (2017) 158:367-77. doi: 10.1210/en.20161333

Conflict of Interest Statement: The authors declare that the research was conducted in the absence of any commercial or financial relationships that could be construed as a potential conflict of interest.

Copyright (c) 2019 Tang, Ding and Zhu. This is an open-access article distributed under the terms of the Creative Commons Attribution License (CC BY). The use, distribution or reproduction in other forums is permitted, provided the original author(s) and the copyright owner(s) are credited and that the original publication in this journal is cited, in accordance with accepted academic practice. No use, distribution or reproduction is permitted which does not comply with these terms. 